\title{
Effects of gasification biochar on plant-available water capacity and plant growth in two contrasting soil types
}

Hansen, Veronika; Hauggaard-Nielsen, Henrik; Petersen, Carsten Tilbæk; Mikkelsen, Teis Nørgaard; Müller-Stöver, Dorette Sophie

Published in:

Soil \& Tillage Research

Link to article, DOI:

10.1016/j.still.2016.03.002

Publication date:

2016

Document Version

Peer reviewed version

Link back to DTU Orbit

Citation (APA):

Hansen, V., Hauggaard-Nielsen, H., Petersen, C. T., Mikkelsen, T. N., \& Müller-Stöver, D. S. (2016). Effects of gasification biochar on plant-available water capacity and plant growth in two contrasting soil types. Soil \& Tillage Research, 161, 1-9. https://doi.org/10.1016/j.still.2016.03.002

\section{General rights}

Copyright and moral rights for the publications made accessible in the public portal are retained by the authors and/or other copyright owners and it is a condition of accessing publications that users recognise and abide by the legal requirements associated with these rights.

- Users may download and print one copy of any publication from the public portal for the purpose of private study or research.

- You may not further distribute the material or use it for any profit-making activity or commercial gain

- You may freely distribute the URL identifying the publication in the public portal 
1 Effects of gasification biochar on plant-available water capacity and plant growth in two contrasting

2 soil types

3 Veronika Hansen ${ }^{a, *}$, Henrik Hauggaard-Nielsen ${ }^{b}$, Carsten T. Petersen a, Teis Nørgaard Mikkelsen ${ }^{c d}$,

4 Dorette Müller-Stöver ${ }^{a}$

5 a University of Copenhagen, Department of Plant \& Environmental Sciences, Thorvaldsensvej 40, 1821

$6 \quad$ Frederiksberg, Denmark

7 b Roskilde University, Department of Environmental, Social and Spatial Change, Universitetsvej 1,

84000 Roskilde, Denmark

9 c Technical University of Denmark, Department of Environmental Engineering, Miljoevej, 2800 Kgs.

10 Lyngby, Denmark

$11 \mathrm{~d}$ Technical University of Denmark, Department of Chemical engineering, Søltofts Plads 229, 2800 Kgs.

12 Lyngby, Denmark

13 * Corresponding author: Veronika Hansen, veha@plen.ku.dk, Tel.: +45 20620522

14

15 
Abstract

Gasification biochar (GB) contains recalcitrant carbon that can contribute to soil carbon sequestration and soil quality improvement. However, the impact of GB on plant-available water capacity (AWC) and plant growth in diverse soil types still needs to be explored.

A pot experiment with spring barley (Hordeum vulgare L.) was conducted to investigate the effect of soil amendment by $1 \%$ straw and wood gasification biochar (SGB and WGB), respectively, on AWC and plant growth responses under two levels of water supply in a temperate sandy loam and a coarse sandy subsoil. In the sandy loam, the reduced water regime significantly affected plant growth and water consumption, whereas the effect was less pronounced in the coarse sand. Irrespective of the soil type, both GBs increased AWC by $17-42 \%$, with the highest absolute effect in the coarse sand. The addition of SGB to coarse sand led to a substantial increase in plant biomass under both water regimes: shoot growth by $40-165 \%$ and root growth by $50-57 \%$. However, no positive effects were achieved by the addition of WGB. In the sandy loam, soil application of GB had no or negative effects on plant growth.

Our results suggest that SGB has considerable potential for enhancing crop productivity in coarse sandy soils by increasing soil water retention and improving root development.

Keywords:

Gasification biochar; Available water capacity; Coarse sand; Barley; Shoot and root growth; Soil 
37 Abbreviations

38 GB Gasification biochar

39 SGB Straw gasification biochar

40 WGB Wood gasification biochar

41 AWC Plant-available water capacity

42 WHC Water holding capacity

43 


\section{Introduction}

45

46

47

An improvement in soil quality and an increase in soil organic matter reduce the exposure and vulnerability of crops to extreme events such as drought (Altieri et al., 2015). The annual soil application of agriculture residues is one of the management tools available for increasing soil organic matter content (Reeves, 1997). However, at the same time the demand for biomass for bioenergy production is growing, putting even more pressure on plant production and the utilization of agriculture and forestry residues (Powlson et al., 2011). Thermal gasification of these residues not only produces sustainable bioenergy (Ahrenfeldt et al., 2013), but also a by-product, gasification biochar (GB), a potentially valuable soil amendment (Müller-Stöver et al., 2012). Depending on the feedstock and specific thermal technology used, GB may contain up to $60 \%$ carbon, which has been shown to be stable towards microbial degradation after soil application and may stay in the soil carbon pool for decades (Hansen et al., 2015). Soil application of GB has the potential to increase the soil organic carbon content, thereby having a beneficial impact on climate change mitigation and soil quality (Sohi et al., 2010).

However, very little research has been undertaken so far on the effect of GB soil amendment on physical soil properties and plant growth. The majority of studies available have been conducted with pyrolysis biochar, the main product of a pyrolysis process conducted under low-oxygen conditions at temperatures of between $400-750^{\circ} \mathrm{C}$ (Kammann et al., 2011; Baronti et al., 2014; Abel et al., 2013). Pyrolysis biochar typically contains $50-80 \%$ carbon, often including a labile carbon fraction that can stimulate microbial activity influencing initial mineralization processes (Bruun et al., 2011). On the other hand, GB is produced at higher temperatures $\left(700-1200^{\circ} \mathrm{C}\right)$, resulting in a by-product with a 
lower C content (20-60\%) but higher stability towards microbial degradation (Müller-Stöver et al., 2012; Bruun et al., 2014; Hansen et al., 2015).

Biochar has a significant adsorbing ability due to its high specific surface area, and its internal porosity may contribute to increasing the water holding capacity (WHC) (Uzoma et al., 2011; Kammann et al., 2011; Bruun et al., 2014) and plant-available water capacity of soil (AWC) (Abel et al., 2013). Especially coarse sandy soils have poor water and nutrient retention, resulting in a risk of drought in dry periods and nutrient losses in wet periods. Hence, large proportions of hydrophilic micropores $(0.2-30 \mu \mathrm{m})$ in biochar, potentially retaining plant-available water, may have the ability to improve AWC in coarse sandy soils (Hardie et al., 2014). Furthermore, decrease in soil bulk density is often reported after biochar application (Rogovska et al., 2014) along with an increase in total porosity (Abel et al., 2013), which may improve the soil structure, resulting in better water retention (Sun and Lu, 2014) and improved root growth (Bruun et al., 2014). Thus, improvement of AWC in biochar-amended soil is apparently not straightforward, but rather a combination of several factors such as soil type, biochar amendment rate and biochar properties (Barnes et al., 2014). In a vineyard field experiment, Baronti et al. (2014) reported that biochar application increased the available water content and leaf water potential during dry periods. In contrast, Jeffery et al. (2015) found that biochar had no effect on soil water retention, which they attribute to the hydrophobicity of the biochar used. Similarly, Hardie et al. (2014) found that acacia biochar had no effect on plant-available water capacity in a sandy loam soil, partly due to the high natural variation in soil physical properties. Biochar amendment has also shown the ability to increase plant root and shoot growth and drought tolerance without increasing soil water availability, improving plant ecophysiological responses related to water status such as leaf 
osmotic potential, stomata resistance and water use efficiency (Kammann et al., 2011; Haider et al.,

87 2014).

88 An improvement in soil structure may be especially beneficial in coarse sandy soils showing high mechanical resistance to root growth due to low compressibility and high friction (Bruun et al., 2014). Rooting depths of only $50-70 \mathrm{~cm}$ are reported in soils with coarse sandy subsoil, while in loamy soils located under the same climatic growing conditions roots may reach depths of $>140 \mathrm{~cm}$ (Madsen, 92 1985). Consequently, the yield potentials of crops can generally not be fully exploited in coarse sandy soils. However, the particle size and pore structure of the specific biochar material may play a significant role when aiming for soil structure improvement (Abel et al., 2013; Sun and Lu, 2014).

Further information about the effects of specific GBs on the properties of different soil types as well as on plant growth under drought stress is required to learn more about how to optimize the use of a study was therefore to evaluate the effects of two contrasting GB materials on the capacity of plantavailable water (AWC) and plant growth responses (shoot and root biomass, leaf water potential, stomatal conductance and carbon isotope discrimination) of spring barley (Hordeum vulgare L.) grown in two different soil types under sufficient and reduced water supply.

102 


\section{Materials and methods}

105

106

107

108

109

110

111

112

113

114

\subsection{Biochar}

Two biochar materials were used in this study: wood gasification biochar (WGB) and straw gasification biochar (SGB). SGB was produced in a Low Temperature Circulating Fluidized Bed gasifier (LT-CFB) at $750^{\circ} \mathrm{C}$ using winter wheat (Triticum aestivum L.) as a feedstock. WGB was produced in a TwoStage gasifier at $1200^{\circ} \mathrm{C}$ from pine wood (Pinus spp.) (Ahrenfeldt et al., 2013). A number of physicochemical characteristics were determined for the GB produced and are shown in Table 1 and 2 . The total content of organic C was measured on an elemental analyzer (FLASH 2000 Organic Elemental Analyzer, Thermo Scientific, Cambridge UK). The elemental composition was determined by ICP-OES after acid digestion (ISO 11885). The specific surface area was determined by the Brunauer-EmmettTeller (BET) method by nitrogen gas sorption at $77 \mathrm{~K}$ (Quantachrome instruments, Boynton Beach, USA). The $\mathrm{pH}$ of the biochar was measured in a 1:5 (w/v) biochar/Milli-Q water suspension by using a pH meter (Mettler-Toledo AG, Switzerland). More details about the production processes, analytical methods and further characteristics of both SGB and WGB can be found in Hansen et al. (2015).

Table 1 here.

Table 2 here.

\subsection{Soils}

The soils used in this study were sandy loam and sandy soils (USDA textural classification). The sandy loam soil was collected from the Ap horizon $(0-25 \mathrm{~cm})$ of a conventional agricultural field on the 
124 Bregentved Estate in Zealand, Denmark ( $\left.55^{\circ} 22^{\prime} \mathrm{N}, 12^{\circ} 05^{\prime} \mathrm{E}\right)$. The sandy soil was collected on the 125 Jyndevad Research Station of Aarhus University, Denmark ( $54^{\circ} 53^{\prime} \mathrm{N}, 9^{\circ} 07^{\prime} \mathrm{E}$ ) from the B horizon (25$126100 \mathrm{~cm}$ depth) and is further termed coarse sandy soil. Both soils were air-dried and sieved to obtain 127 a fraction $\leq 2 \mathrm{~mm}$. The soil properties are shown in Table 3.

128 Table 3 here

129

130

\subsection{Experiment setup}

131 The experiment was conducted in the Ris $\varnothing$ Environmental Risk Assessment Facility (RERAF) phytotron

132 at the Technical University of Denmark, Roskilde campus, Denmark. The experiment involved 12 133 treatments with four replicates: two soil types, three GB amendments (control without GB, 1\% WGB and $1 \%$ SGB respectively) and two water regimes (70\% and $30 \%$ of the water-holding capacity (WHC) of the control treatment respectively). It was decided to base the water supply on the WHC of the control treatment to avoid effects simply caused by a higher water supply to the biochar-amended pots. The WHC was determined for each soil type in $28 \mathrm{~cm}$-high PVC pots with an inner diameter of 10 $\mathrm{cm}$, equipped with a wick system at the bottom allowing drainage preventing eventual excessive accumulation of water near the lower boundary (Fig. 1). To determine WHC, the sandy loam soil was packed into the pots using pressure of a metal piston of the same diameter as the pot, which resulted

141 in a bulk density of $1.47 \mathrm{~g} \mathrm{~cm}^{-3}$ in the control treatment. The coarse sandy soil was added to the pot without pressure and had a bulk density of $1.63 \mathrm{~g} \mathrm{~cm}^{-3}$ in the control treatment. The pots with soil 
144 preventing evaporation. The recorded weight of the water held in the soil after drainage was taken as 145 WHC.

146 Prior to the experiment, the dry soil was weighed into plastic bags to give $2.6 \mathrm{~kg}$ of sandy loam soil 147 and $3 \mathrm{~kg}$ of coarse sandy soil respectively. Nutrients were added in a liquid solution to the soil in each 148 bag at a rate of $60 \mathrm{mg} \mathrm{P,} 40 \mathrm{mg} \mathrm{Mg}, 124 \mathrm{mg} \mathrm{S}, 166 \mathrm{mg} \mathrm{K}, 3.4 \mathrm{mg} \mathrm{Mn}, 1.2 \mathrm{mg} \mathrm{Zn}, 0.2 \mathrm{mg} \mathrm{Cu}$ and $0.1 \mathrm{mg}$ $149 \mathrm{Mo} \mathrm{kg}^{-1}$ soil (as $\mathrm{KH}_{2} \mathrm{PO}_{4}, \mathrm{MgSO}_{4}, \mathrm{~K}_{2} \mathrm{SO}_{4}, \mathrm{MnSO}_{4}, \mathrm{ZnSO}_{4}, \mathrm{CuSO}_{4}, \mathrm{Na}_{2} \mathrm{MoO}_{4}$ ). The soil was thoroughly 150 mixed with $1 \%$ of the GB material on a dry weight basis. The WGB was sieved to obtain a fraction $<1$ $151 \mathrm{~cm}$. The mixtures and control treatments were packed with the same pressure as for the WHC 152 determination, respectively. With these densities, $1 \%$ of GB corresponds to approximately $36 \mathrm{t} \mathrm{ha}{ }^{-1}$ in 153 a sandy loam soil and approximately $40 \mathrm{t} \mathrm{ha}^{-1}$ in a coarse sandy soil, if incorporated to $25 \mathrm{~cm}$ soil 154 depth.

155 Prior to the experiment, the conditions in the phytotron were set as follows: The daylight period was 156 set to 16 hours and the environmental parameters were controlled as follows (day/night): 157 temperature $\left(22 / 16^{\circ} \mathrm{C}\right)$, photosynthetically active radiation $\left(400 / 0 \mu \mathrm{mol} \mathrm{m} \mathrm{m}^{-2} \mathrm{~s}^{-1}\right)$ and relative air 158 humidity (55/70\%). All the pots were watered from the top to $80 \%$ of the WHC of the control 159 treatments during the first week of the experiment to avoid dry soil at the bottom of the pots. All pots 160 received $100 \mathrm{mg} \mathrm{N} \mathrm{kg}^{-1}$ soil in a liquid solution after irrigation before sowing and the same amount 21 161 days after sowing. After one week, five spring barley (Hordeum vulgare L., cv. Quench) seeds were 162 sown at approximately $1 \mathrm{~cm}$ depth and two water regimes were established by watering the pots to $16330 \%$ and $70 \%$ of control treatment WHC, respectively. However, treatments under the $30 \%$ water 164 regime were watered to reach $50 \%$ WHC of the control up to 10 days after sowing to secure 
165 germination, whereupon 30\% WHC was maintained for the rest of the experiment. Plants were

166 thinned to three plants per pot and supported with wooden plant sticks to avoid lodging. Each pot 167 received $50 \mathrm{~g}$ plastic beads on the top of the soil to minimize soil water evaporation. The pots were 168 watered to weight from above every second or third day during the first weeks and daily during the 169 final week of the experiment. No drainage from the pots was observed during the experiment. 170 Cumulative water consumption was calculated from the day on which all the plants had been 171 germinated until the day of harvest as the sum of water loss from each treatment recorded at each 172 watering time

$173 \quad$ Fig. 1 here

$174 \quad$ 2.4. Plant ecophysiological measurements and yield

175 Stomatal conductance was used as an indicator of plant drought stress, as plants close stomata to 176 reduce water loss and consequently stomatal conductance decreases. Stomatal conductance 177 measurements using a leaf porometer SC-1 model (Decagon Devices) was initiated 25 days after 178 sowing and was conducted two hours after the light had been switched on. Measurements were 179 performed on the upper surface of the youngest fully emerged leaf, approximately $5 \mathrm{~cm}$ from the stem. Three measurements per pot were taken.

Leaf water potential was used as an indicator of soil water availability. The leaf water potential was measured 37 days after sowing in a pressure chamber using the digital plant moisture system Skye SKPM 1400 connected to pressurized air (Skye Instruments Ltd., United Kingdom) on the first two fully expanded leaves per pot. The measurements were performed as "pre-dawn measurements" during 
185 the night, three hours after nightfall, which was approximately 20 hours after the last watering, and 186 then continued for four hours.

187 The plants were harvested six weeks after sowing by cutting the aboveground plants by hand just 188 above the soil surface. The roots were isolated by gently pressing the soil out of the pot, followed by 189 carefully rinsing the roots with water. Both shoots and roots were dried in an oven for 48 hours at $19070^{\circ} \mathrm{C}$ and their dry weight determined.

191 Carbon isotope discrimination was used as an indicator of water use efficiency. Carbon isotope 192 discrimination was analyzed on the harvested aboveground dried plants. Plant samples were first 193 coarsely ground in a plant mill to pass a $4 \mathrm{~mm}$ sieve and secondly finely ground in a ball mill and 194 weighed into tin capsules. The carbon isotope composition was determined on an elemental analyzer 195 (FLASH 2000 Organic Elemental Analyzer, Thermo Scientific, Cambridge, UK) coupled to an isotope 196 ratio mass spectrometer using the Vienna PeeDeeBelemnite as a standard. The carbon isotope 197 discrimination $(\Delta)$ was calculated as:

198

$$
\Delta(\%)=\left[\frac{\left(\delta_{\text {air }}-\delta_{\text {plant }}\right)}{\left(1+\delta_{\text {plant }}\right)}\right] * 1000(\text { Equation } 1)
$$
where $\delta_{\text {air }}$ was assumed to be -0.008 (Farquhar et al., 1989).

\subsection{Soil measurements}


202 Soil $\mathrm{pH}$ was only measured on soil samples from the $70 \%$ WHC treatments, using a soil-water

203 suspension of $5 \mathrm{~g}$ soil and $25 \mathrm{ml}$ of Milli-Q water ( $\mathrm{pH}$ meter Mettler-Toledo AG, Switzerland), 204 assuming no $\mathrm{pH}$ effects of the water regimes.

205 Pots under the $30 \%$ WHC water regime were used to determine water retention, as the root growth 206 in those pots was lower compared to the pots under 70\% WHC. This made it possible to take soil 207 samples from the bottom of the pots with less root content. Undisturbed soil samples were taken 208 after harvest in a metal ring of $100 \mathrm{~cm}^{3}$. The ring was pressed into the soil from the bottom end of the 209 pot. The soil content of the pot was carefully pushed out of the pot in order to minimize disturbance 210 when cutting the intact ring with soil. The samples were saturated by adding de-aired water from the 211 bottom end and leaving the samples at zero tension for 24 hours. Moisture retention was determined 212 at suctions of $50 \mathrm{~cm}$ (for coarse sand) or $100 \mathrm{~cm}$ (for sandy loam) using a tension table with a hanging water column, and at 15.5 bars suction (both soil types) using a suitable pressure plate extractor and 214 pressure chamber (Dane and Hopmans, 2002). These suction levels were chosen to represent field 215 capacity (pF 1.7 in coarse sand and 2.0 in sandy loam) and permanent wilting point (permanent wilting point at pF 4.2). The samples were left for 72 hours at 50 and $100 \mathrm{~cm}$ tension, and for 21 days

217 at pF 4.2 to reach equilibrium. The measurements were performed in quadruplicate per treatment, 218 i.e. per combination of soil type and GB level.

219 Moisture content at equilibrium $\left(\mathrm{m}_{\mathrm{w}}, \mathrm{g}\right)$ was obtained as the difference between the masses of moist 220 and oven-dried soil $\left(105^{\circ} \mathrm{C}\right)$. The volumetric moisture content $\left(\theta, \mathrm{cm}^{3} \mathrm{~cm}^{-3}\right)$ of the ring samples (i.e. at 221 field capacity) was calculated as water volume divided by sample volume $\left(100 \mathrm{~cm}^{3}\right)$ using a water 222 density of $\rho_{\mathrm{w}}=1.00 \mathrm{~g} \mathrm{~cm}^{-3}$. Dry bulk density was calculated from ring samples as the ratio of oven dry 
224 calculated as:

$$
\theta_{4.2}=w \frac{\rho_{b}}{\rho_{w}} \text { (Equation 2) }
$$

226 where $w$ is the gravimetric moisture content $\left(w=m_{w} / m_{s d}\right)$ and $\rho_{b}$ is the average dry bulk density 227 measured on ring samples for the same treatment.

228 The plant AWC was calculated as the difference between volumetric water content at field capacity 229 and permanent wilting point.

\subsection{Statistical analysis}

232 Statistical analysis of the data was performed in $\mathrm{R}$, version 0.98.1103. The significant interaction effect 233 of the soil type, water regime and GB addition was assessed using a three-way analysis of variance 234 (ANOVA). The effect of the water regime within each soil type was analyzed by two-way ANOVA. The differences between treatments within each soil type and water regime were analyzed using leastsquare means from the R-package Ismeans (Lenth and Herv, 2015). P values were adjusted using the Tukey method. All differences at $\mathrm{P}<0.05$ were reported as significant. Prior to analysis, data were tested for homogeneity of variance and normality of residuals using the Wally plot (R MESS package) and log or square root transformed if necessary. 


\section{Results}

241

\subsection{Shoot and root growth}

242 Shoot and root growth was affected by soil type, water regime and GB addition and type (Fig. 2). The results from ANOVA analysis of single and interaction effects are shown in Table 4. Shoot and root

244 growth was lower when barley was grown in coarse sandy soil compared to the sandy loam ( $p=$ 0.0001). In the sandy loam, the $30 \%$ WHC regime had a significantly negative impact on both shoot and root growth $(p<0.0001)$. Neither SGB nor WGB addition had any effect on root growth under either water regime, while shoot growth decreased by the WGB addition under the 70\% WHC regime. In the coarse sandy soil, the $30 \%$ WHC regime had no effect on shoot or root growth in the control treatments compared to the $70 \% \mathrm{WHC}$ regime. The addition of SGB to the coarse sandy soil increased shoot growth by $165 \%$ and root growth by $50 \%$ under the $70 \%$ WHC regime; however the shoot biomass was still only half of the biomass obtained in the sandy loam soil. Under the $30 \%$ WHC regime, the addition of SGB increased shoot growth by $40 \%$ and root growth by $57 \%$. In contrast, the addition of WGB to coarse sandy soil had no effect on shoot growth under $70 \%$ WHC, a negative effect on shoot growth under $30 \% \mathrm{WHC}$, and no effect on root growth under either water regime.

\section{Fig. 2 here}

256 Table 4 here

\subsection{Plant ecophysiological responses}

258

Generally the water regime had an effect on the plant ecophysiological responses, while the addition of GB had variable effects (Table 4). The stomatal conductance of barley leaves decreased significantly 
under the $30 \%$ WHC regime compared to the $70 \%$ WHC regime in both soil types $(p<0.001$, Table 4$)$.

261 In the sandy loam soil, stomatal conductance decreased when amended with WGB under the $70 \%$

262 WHC regime compared to the control, while there was no effect of GB addition under the $30 \%$ WHC

263 regime. In the coarse sandy soil, the application of WGB significantly decreased stomatal conductance

264 under $30 \%$ WHC, whereas there was no effect of GB under the $70 \%$ WHC. The leaf water potential of

265 barley leaves varied and was not significantly affected either by the water regimes or by GB addition 266 (data not shown).

267 The carbon isotope discrimination was highest under the 70\% WHC regime and decreased 268 significantly under the $30 \%$ WHC regime in both soil types $(p<0.0001)$ (Fig. 3 c,d), confirming the 269 stomatal conductance measurements. GB amendments had no effect on carbon isotope 270 discrimination (Table 4).

271 The cumulative water consumption of barley plants overall corresponded to plant growth (Fig. 2, 4).

272 In the sandy loam soil, cumulative water consumption was affected by the water regime but not by

273 GB addition, being highest under the 70\% WHC regime (Fig. 4). In contrast, in the coarse sandy soil it 274 was affected by both water regime and GB addition. SGB addition increased cumulative water 275 consumption in the $70 \%$ WHC regime, while the addition of WGB decreased it under both water 276 regimes.

277 Fig. 3 and 4 here.

278

\subsection{Soil measurements}


280 The application of GB did not have any effect on bulk density in either of soil types (data not shown).

281 Both soil type and GB addition affected field capacity, permanent wilting point and AWC (Fig. 5), that 282 were generally higher in the sandy loam soil compared to the coarse sand. The addition of WGB 283 increased the permanent wilting point by $9 \%$ in sandy loam and $43 \%$ in coarse sand, while the SGB 284 addition had no effect. The field capacity and AWC were increased by both GB types in both soil 285 types, although the effect was highest in the coarse sandy soil treatments. The AWC was increased by $28618 \%$ in SGB and $17 \%$ in WGB treatment in sandy loam, while it was increased by $42 \%$ in SGB and $31 \%$ 287 in WGB treatment in coarse sand. The addition of both GBs increased the $\mathrm{pH}$ of the coarse sandy soil 288 (Fig. 6). The application of WGB had the highest impact and increased the pH from 6.2 to 8.3. In the 289 sandy loam soil, pH was only increased by WGB application.

$290 \quad$ Fig 5 and 6 here 


\section{Discussion}

292

293

294

295

296

297

298

299

300

301

302

303

304

305

306

307

308

309

310

311

\subsection{Effect of reduced water supply on plants}

The reduced water supply affected root and shoot growth and plant water consumption in the sandy loam soil considerably, while in the coarse sandy soil the differences between the two water regimes were generally less pronounced. Plant growth in the control treatments in coarse sand was approximately the same under both water regimes. This may be due to the fact that coarse sandy soil under $30 \%$ WHC is not as close to the wilting point as sandy loam. However, the main reason is most likely the limited root growth caused by mechanical resistance, which often occurs even under moderately wet conditions (Whalley et al., 2006; Bengough et al., 2011). The reason for this is the high soil strength of sandy particles, as greater pressure is required to push the particles aside so that the root can penetrate (Barber, 1995). The applied additional water may have accumulated in the bottom of the pot with fewer roots and was therefore not fully available for root uptake. Accordingly, the negative effects of the reduced water regime on stomatal conductance and carbon isotope discrimination in coarse sand were limited and not significantly different from the $70 \%$ WHC treatment. In contrast, in the sandy loam stomatal conductance and carbon isotope discrimination decreased significantly under the $30 \%$ WHC treatments as a consequence of plant water stress, which is in accordance with other studies (Kammann et al., 2011; Kottmann et al., 2014). The exposure of plants to drought stress typically also decreases leaf water potential (Farooq et al., 2009). However, this was not observed in the current study, probably because the leaf water potential was sampled pre-dawn and therefore the plants can compensate with a continuous water uptake during nighttime in contrast to stomatal conductance that was measured during daytime (Schulze et al., 1985). 


\subsection{The effect of SGB in sandy loam soil}

314 In the sandy loam soil, the addition of SGB increased water content at field capacity and AWC. In

315 other investigations, the effects of biochar on the hydraulic properties of loamy soils are reported to vary. Several studies showed positive effects of biochar amendment to loamy sand and sandy loam soils on field capacity and AWC (Abel et al., 2013; Peake et al., 2014), while no effects of biochar amendment on field capacity and permanent wilting point were observed in a study by Hardie et al. (2013). The varying effects are caused by the interaction of many factors such as soil texture, soil organic matter content, physicochemical biochar characteristics and biochar application rate. For instance, Abel et al. (2013) observed the greatest increase in AWC by biochar application in sandy soils and no effect on soils with high organic matter content. In this study, the GB-induced increase in field capacity and AWC was not expected to lead to an increase in shoot and root growth, as all treatments were kept at either $30 \%$ or $70 \%$ WHC of the control soil. Hence, the GB-amended soils did not receive higher amounts of irrigation water compared to the control soils. However, a beneficial effect of increased AWC by GB on plant growth can be expected under field conditions, e.g. in the case of thorough wetting followed by subsequent drought. The addition of SGB did not have any other positive effects on shoot or root growth in the sandy loam soil under $70 \%$ WHC, which is probably due to the soil's moderate clay and SOM content and a soil texture that enables root development for sufficient water uptake to support plant growth. However, no positive effects of SGB on plant growth under drought stress were observed either. 


\subsection{The effect of SGB in coarse sandy soil}

334 In the coarse sandy soil, SGB increased water content at field capacity and AWC as well, which has 335 also been documented in other studies on coarse sandy soils (Uzoma et al., 2011; Abel et al., 2013; 336 Barnes et al., 2014). The addition of SGB resulted in considerably increased root and shoot growth under both water regimes. Similar results were obtained by Kammann et al. (2011), where biochar application to poor sandy soil increased the shoot and root growth of quinoa. In addition, the authors reported an improvement in plant water status after the application of biochar when the same limited amount of water was applied to all treatments. This contrasts with the present study where plant physiological responses did not differ from the control treatments, even when biomass production was significantly increased. We cannot completely exclude that the positive impact on plant growth was caused by the addition of plant nutrients - such as $\mathrm{K}$ - to the nutrient-poor sandy soil, although it was intended to avoid fertilizer effects by adding sufficient nutrients to all treatments. However, the addition of mineral nutrients in WGB did not show any benefits, therefore we assume that the great positive effect of SGB on plant biomass in coarse sand was most likely due to reduced mechanical impedance to root growth. The importance of the soil structure can be corroborated by the fact that in contrast to the sandy loam, the $70 \%$ water regime did not have a positive effect on the plants in the coarse sandy soil in the non-amended control treatments, as discussed in section 4.1. We hypothesize that when adding SGB to sandy soil, some of its small particles may settle between the coarse sand particles, thereby reducing friction, whereas others may transform large drainable pores into smaller pores. Smaller pores can improve the water supply by increasing the AWC and contact between the roots and the water. This is consistent with the findings of Bruun et al. (2014), who 
reported that SGB increased water retention in coarse sandy soil and improved root growth of barley,

355 increasing the grain yield by $22 \%$.

356 Under field conditions, the increased AWC and improved root growth may lead to improvements in

357 both water and nutrient retention and hence decrease the leaching of mobile nutrients, such as

358 nitrate (Sika and Hardie, 2014). Improving the quality of coarse sandy soils has global potential, since

359 the lack of yield potential utilization caused by limited AWC and poor root development affects

360 agricultural production in many regions of the world, for example in parts of Africa dominated by poor

361 sandy soils (Sika and Hardie, 2014) or areas in Denmark dominated by coarse sandy subsoils (Bruun et

362 al., 2014). However, the underlying mechanisms for improving the soil structure of coarse sandy soil

363 by SGB need further investigation.

364

365

\subsection{The effect of $W G B$}

WGB increased water content at field capacity and AWC to the same extent as SGB, but no positive effect on plant growth could be observed after the application of WGB in any of the soils or treatments. Quite the opposite, in fact, since WGB even decreased shoot growth under the $30 \%$ WHC water regime compared to the control in the coarse sandy soil. The lack of a positive effect of WGB in this soil might be due to its higher proportion of larger particles (53\% larger than $0.125 \mathrm{~mm}$ ) compared to SGB. Due to fewer but larger particles heterogeneously distributed in the soil, WGB may not be able to change the skeleton of the soil matrix and increase the water retaining pore space volume to the same degree as SGB. It may also be difficult for the roots to utilize water retained by large particles of WGB. In fact, WGB addition increased the water retention at permanent wilting 
375 point, indicating that WGB binds more water that is then non-available to plants. This is most likely 376 due to the high SSA and thus increased microporosity of WGB (Abel et al., 2013) and may be a reason 377 for the reduced shoot and root growth and stomatal conductance under the $30 \%$ WHC water regime 378 in coarse sandy soil. However, as the WGB addition also resulted in decreased stomatal conductance 379 and a reduction in plant biomass under the 70\% WHC treatment in the sandy loam soil without a 380 decrease in water consumption, we cannot exclude other detrimental effects of this material on plant 381 growth. The WGB was most efficient at increasing soil $\mathrm{pH}$. Although potentially beneficial for soil 382 fertility and crop production in acidic soils (Deal et al., 2012), this may reduce the availability of 383 certain nutrients in already alkaline soils. However, since pH was not significantly different in either 384 GB-amended treatment in the sandy loam, it seems unlikely that increased soil pH was the only 385 reason for reduced plant growth in the WGB treatment. 


\section{Conclusions}

388 The reduced water regime significantly affected plant ecophysiological responses, plant growth and 389 water consumption in the sandy loam soil, whereas it only had a small or no effect in the coarse sandy soil. Both gasification biochars increased the plant-available water content in both the sandy loam and the coarse sandy soil. However, the two contrasting GB materials had different effects on plant growth in the two soil types tested, suggesting that the mitigation of specific soil restraints needs specifically adapted GB materials. The application of WGB had either no effect or slightly negative effects on plant ecophysiological responses and growth. Under which conditions WGB with its interesting properties such as high SSA, $\mathrm{pH}$ and porosity can positively affect plant growth has to be the subject of future research. The greatest benefits were observed on coarse sandy soil where SGB markedly increased root and shoot growth under both water regimes. These results suggest that there is great potential in the ability of SGB to increase soil $\mathrm{pH}$, water retention and root development in order to improve crop productivity on the often poor coarse sandy soils in many parts of the world.

400 However, the results of this study are based on a pot experiment with disturbed soil and need to be 401 verified in field experiments. 


\section{Acknowledgements}

403 This research was supported by a grant from the VILLUM Foundation VKR022521. We are grateful to 404 DONG Energy for providing us with the straw gasification biochar samples, the Department of 405 Chemical and Biochemical Engineering at the Technical University of Denmark for the wood 406 gasification biochar samples and Bregentved Estate for providing the soil. We thank Mette Flodgaard 407 for her technical assistance and Anders Tolver for his help with statistical analysis. 


\section{References:}

Abel, S., Peters, A., Trinks, S., Schonsky, H., Facklam, M., Wessolek, G., 2013. Impact of biochar and hydrochar addition on water retention and water repellency of sandy soil. Geoderma 202-203, 183-191. doi:10.1016/j.geoderma.2013.03.003

Ahrenfeldt, J., Thomsen, T.P., Henriksen, U., Clausen, L.R., 2013. Biomass gasification cogeneration - A review of state of the art technology and near future perspectives. Appl. Therm. Eng. 50, 14071417. doi:10.1016/j.applthermaleng.2011.12.040

Altieri, M. a., Nicholls, C.I., Henao, A., Lana, M. a., 2015. Agroecology and the design of climate change-resilient farming systems. Agron. Sustain. Dev. doi:10.1007/s13593-015-0285-2

Barber, S.A., 1995. Modelling nutrient uptake by plant roots growing in soil, in: Soil Nutrient Bioavailability: A Mechanistic Approach. pp. 110-132.

Barnes, R.T., Gallagher, M.E., Masiello, C. a., Liu, Z., Dugan, B., 2014. Biochar-Induced Changes in Soil Hydraulic Conductivity and Dissolved Nutrient Fluxes Constrained by Laboratory Experiments. PLoS One 9, e108340. doi:10.1371/journal.pone.0108340

Baronti, S., Vaccari, F.P., Miglietta, F., Calzolari, C., Lugato, E., Orlandini, S., Pini, R., Zulian, C., Genesio, L., 2014. Impact of biochar application on plant water relations in Vitis vinifera (L.). Eur. J. Agron. 53, 38-44. doi:10.1016/j.eja.2013.11.003

Bengough, a. G., McKenzie, B.M., Hallett, P.D., Valentine, T. a., 2011. Root elongation, water stress, and mechanical impedance: A review of limiting stresses and beneficial root tip traits. J. Exp. Bot. 62, 59-68. doi:10.1093/jxb/erq350

Bruun, E.W., Hauggaard-Nielsen, H., Ibrahim, N., Egsgaard, H., Ambus, P., Jensen, P. a., DamJohansen, K., 2011. Influence of fast pyrolysis temperature on biochar labile fraction and shortterm carbon loss in a loamy soil. Biomass and Bioenergy 35, 1182-1189. doi:10.1016/j.biombioe.2010.12.008

Bruun, E.W., Petersen, C.T., Hansen, E., Holm, J.K., Hauggaard-Nielsen, H., 2014. Biochar amendment to coarse sandy subsoil improves root growth and increases water retention. Soil Use Manag. 30, 109-118. doi:10.1111/sum.12102

Dane, J.H., Hopmans, J.W., 2002. Water retention and storage: Laboratory methods, in: Dane, J.H., Topp, G.C. (Eds.), Methods of Soil Analysis. Part 4. Physical Methods. SSSA Book Ser. 5. SSSA, Madison, WI, pp. 671-720.

Deal, C., Brewer, C.E., Brown, R.C., Okure, M. a. E., Amoding, A., 2012. Comparison of kiln-derived and gasifier-derived biochars as soil amendments in the humid tropics. Biomass and Bioenergy 37, 161-168. doi:10.1016/j.biombioe.2011.12.017

Farooq, M., Wahid, a., Kobayashi, M., Fujita, D., Basra, S.M. a., 2009. Review article Plant drought stress : e ff ects, mechanisms and management. Agron. Sustain. Dev. 29, 185-212. doi:10.1051/agro:2008021 
Farquhar, G.D., Ehleringer, J.R., Hubick, K.T., 1989. Carbon Isotope Discrimination and Photosynthesis. Annu. Plant Physiol. Plant Mol. Biol 40, 503-537.

Haider, G., Koyro, H.-W., Azam, F., Steffens, D., Müller, C., Kammann, C., 2014. Biochar but not humic acid product amendment affected maize yields via improving plant-soil moisture relations. Plant Soil. doi:10.1007/s11104-014-2294-3

Hansen, V., Müller-Stöver, D., Ahrenfeldt, J., Kai, J., Birk, U., Hauggaard-nielsen, H., 2015. ScienceDirect Gasification biochar as a valuable by-product for carbon sequestration and soil amendment. Biomass and Bioenergy 2. doi:10.1016/j.biombioe.2014.10.013

Hardie, M., Clothier, B., Bound, S., Oliver, G., Close, D., 2014. Does biochar influence soil physical properties and soil water availability? Plant Soil 1-15. doi:10.1007/s11104-013-1980-x

Jeffery, S., Meinders, M.B.J., Stoof, C.R., Bezemer, T.M., van de Voorde, T.F.J., Mommer, L., van Groenigen, J.W., 2015. Biochar application does not improve the soil hydrological function of a sandy soil. Geoderma 251-252, 47-54. doi:10.1016/j.geoderma.2015.03.022

Kammann, C.I., Linsel, S., Gößling, J.W., Koyro, H.-W., 2011. Influence of biochar on drought tolerance of Chenopodium quinoa Willd and on soil-plant relations. Plant Soil 345, 195-210. doi:10.1007/s11104-011-0771-5

Kottmann, L., Schittenhelm, S., Giesemann, A., 2014. Suitability of carbon isotope discrimination, ash content and single mineral concentration for the selection of drought-tolerant winter rye. Plant Breed. 133, 579-587. doi:10.1111/pbr.12198

Lenth, R., Herv, M., 2015. Package “Ismeans ."

Madsen, H.B., 1985. Distribution of spring barley roots in Danish soils of different texture and under different climatic conditions. Plant Soil 88, 31-43.

Müller-Stöver, D., Ahrenfeldt, J., Holm, J.K., Shalatet, S.G.S., Henriksen, U., Hauggaard-Nielsen, H., 2012. Soil application of ash produced by low-temperature fluidized bed gasification: effects on soil nutrient dynamics and crop response. Nutr. Cycl. Agroecosystems 94, 193-207. doi:10.1007/s10705-012-9533-x

Peake, L.R., Reid, B.J., Tang, X., 2014. Quantifying the influence of biochar on the physical and hydrological properties of dissimilar soils. Geoderma 235-236, 182-190. doi:10.1016/j.geoderma.2014.07.002

Powlson, D.S., Glendining, M.J., Coleman, K., Whitmore, A.P., 2011. Implications for Soil Properties of Removing Cereal Straw: Results from Long-Term Studies. Agron. J. 103, 279. doi:10.2134/agronj2010.0146s

Reeves, D.W., 1997. The role of soil organic matter in maintaining soil quality in continuous cropping systems. Soil Tillage Res. 43, 131-167. doi:10.1016/S0167-1987(97)00038-X

Rogovska, N., Laird, D. a., Rathke, S.J., Karlen, D.L., 2014. Biochar impact on Midwestern Mollisols and maize nutrient availability. Geoderma 230-231, 34-347. doi:10.1016/j.geoderma.2014.04.009 
Schulze, E.-D., Cermak, J., Matyssek, R., Penka, M., Zimmermann, R., Vasicek, F., Gries, W., Kucera, J., 1985. Canopy transpiration and water fluxes in the xylem of the trunk of Larix and Picea trees - a comparison of xylom flow porometer and cuvette measurements. Oecologia 66, 475-483.

Sika, M.P., Hardie, a. G., 2014. Effect of pine wood biochar on ammonium nitrate leaching and availability in a South African sandy soil. Eur. J. Soil Sci. 65, 113-119. doi:10.1111/ejss.12082

Sohi, S.P., Krull, E., Lopez-Capel, E., Bol, R., 2010. A review of biochar and its use and function in soil. Adv. Agron. 105, 47-82. doi:10.1016/S0065-2113(10)05002-9

Sun, F., Lu, S., 2014. Biochars improve aggregate stability, water retention, and pore-space properties of clayey soil. J. Plant Nutr. Soil Sci. 177, 26-33. doi:10.1002/jpln.201200639

Uzoma, K.C., Inoue, M., Andry, H., Zahoor, A., Nishihara, E., 2011. Influence of biochar application on sandy soil hydraulic properties and nutrient retention. J. Food, Agric. Environ. 9, 1137-1143.

Whalley, W.R., Clark, L.J., Gowing, D.J.G., Cope, R.E., Lodge, R.J., Leeds-Harrison, P.B., 2006. Does soil strength play a role in wheat yield losses caused by soil drying? Plant Soil 280, 279-290. doi:10.1007/s11104-005-3485-8 
496 Table 1 Chemical characterization and particle size distribution of the SGB (straw gasification biochar)

497 and WGB (wood gasification biochar) materials (modified from Hansen et al. 2015)

\begin{tabular}{llll}
\hline Parameter & Unit & SGB & WGB \\
$\mathbf{C}$ & $\mathrm{g} \mathrm{kg}^{-1}$ & 468 & 653 \\
$\mathbf{P}$ & $\mathrm{g} \mathrm{kg}^{-1}$ & 4 & 3.4 \\
$\mathbf{K}$ & $\mathrm{g} \mathrm{kg}^{-1}$ & 72 & 25 \\
$\mathbf{S}$ & $\mathrm{g} \mathrm{kg}^{-1}$ & 1.2 & 0.17 \\
$\mathbf{M g}$ & $\mathrm{g} \mathrm{kg}^{-1}$ & 4.6 & 5.9 \\
$\mathbf{C a}$ & $\mathrm{g} \mathrm{kg}^{-1}$ & 18 & 52 \\
$\mathbf{F e}$ & $\mathrm{g} \mathrm{kg}^{-1}$ & 1.7 & 16 \\
$\mathbf{Z n}$ & $\mathrm{mg} \mathrm{kg}^{-1}$ & 64 & 160 \\
$\mathbf{C u}$ & $\mathrm{mg} \mathrm{kg}^{-1}$ & 13 & 55 \\
pH (water) & & 11.6 & 11.1 \\
Particle size distribution & $\%$ of dry mass & & \\
$<\mathbf{0 . 0 4 5}$ & $\mathrm{mm}$ & 89.3 & 33 \\
$\mathbf{0 . 0 4 5 - 0 . 1 2 5}$ & $\mathrm{mm}$ & 10.3 & 13.7 \\
$>\mathbf{0 . 1 2 5}$ & $\mathrm{mm}$ & 0.3 & 53.3 \\
\hline
\end{tabular}


499 Table 2 Brunauer-Emmett-Teller (BET) specific surface area (SSA) and pore volume of straw 500 gasification biochar (SGB) and wood gasification biochar (WGB). WGB was divided into two size 501 fractions (modified from Hansen et al. 2015)

\begin{tabular}{lccc}
\hline Biochar & Particle size $(\mathrm{mm})$ & SSA $\left(\mathrm{m}^{2} \mathrm{~g}^{-1}\right)$ & Pore volume $\left(\mathrm{cm}^{3} \mathrm{~g}^{-1}\right)$ \\
\hline SGB & $0-1$ & 75 & 0.04 \\
WGB & $0-0.5$ & 426 & 0.52 \\
WGB & $0.5-1$ & 1027 & 0.58 \\
\hline
\end{tabular}

502

503 
504 Table 3 Soil texture, pH, soil organic matter (SOM) and soil water-holding capacity (WHC)

\begin{tabular}{lccccccc}
\hline & Clay \% & Silt \% & $\begin{array}{c}\text { Fine sand } \\
\%\end{array}$ & $\begin{array}{c}\text { Coarse sand } \\
\%\end{array}$ & $\begin{array}{c}\mathrm{pH} \\
\text { (water) }\end{array}$ & SOM \% & WHC \% \\
\hline $\begin{array}{l}\text { Sandy loam } \\
\text { Coarse }\end{array}$ & 14 & 14 & 47 & 24 & 7.9 & 3.4 & 29 \\
sand & 2.3 & 0.9 & 18.9 & 77.9 & 6.8 & 0.3 & 19 \\
\hline
\end{tabular}


506 Table 4 Results from three-way anova of single and interactions effects of soil type (Soil), gasification

507 biochar (GB), water regime (WR) on shoot and root growth of spring barley, stomatal conductance

508 (SC) and carbon isotope discrimination (CID)

\begin{tabular}{|c|c|c|c|c|c|c|c|c|}
\hline \multirow[t]{2}{*}{ Factors } & \multicolumn{2}{|l|}{ Shoots } & \multicolumn{2}{|l|}{ Roots } & \multicolumn{2}{|l|}{ SC } & \multicolumn{2}{|l|}{ CID } \\
\hline & F-value & $p$-value & F-value & $p$-value & F-value & p-value & F-value & $p$-value \\
\hline Soil & 676.9 & $<0.001$ & 44.5 & $<0.001$ & 1.1 & N.S. & 0.2 & N.S. \\
\hline GB & 52.4 & $<0.001$ & 3.2 & 0.05 & 4.9 & 0.01 & 1.1 & N.S. \\
\hline WR & 503.8 & $<0.001$ & 33.1 & $<0.001$ & 101.8 & $<0.001$ & 148.5 & $<0.001$ \\
\hline Soil x GB & 14.9 & $<0.001$ & 1.9 & N.S. & 1.7 & N.S. & 0.5 & N.S. \\
\hline Soil x WR & 274.5 & $<0.001$ & 25.7 & $<0.001$ & 4.4 & 0.04 & 32.1 & $<0.001$ \\
\hline GB $\times$ WR & 11.2 & $<0.001$ & 1.7 & N.S. & 2.8 & N.S. & 0.6 & N.S. \\
\hline Soil x GB x WR & 3.2 & 0.05 & 1.5 & N.S. & 8.1 & 0.001 & 0.7 & N.S. \\
\hline
\end{tabular}




\section{0}

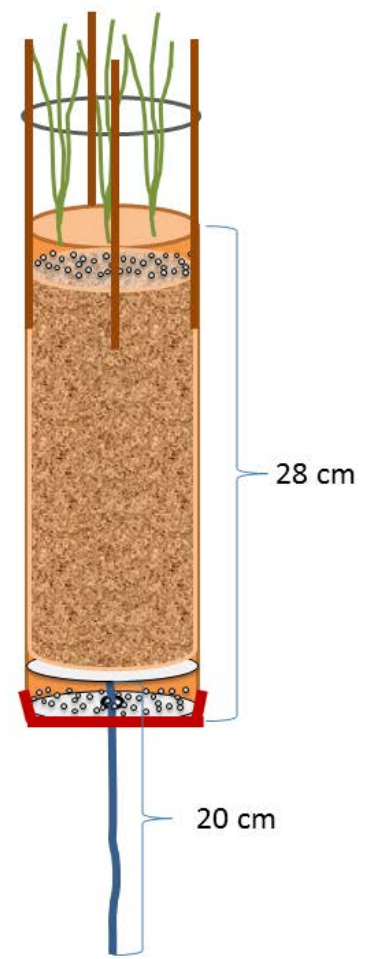

511 Fig. 1 The experimental setup of pots with a drainage system consisting of two layers of felted fabric 512 in the bottom with a $1 \mathrm{~cm}$-thick layer of $5 \mathrm{~mm}$ plastic beads in between, and a $20 \mathrm{~cm}$-long cotton 513 wick, attached to the inner felted fabric, passing through those layers

514

515

516 


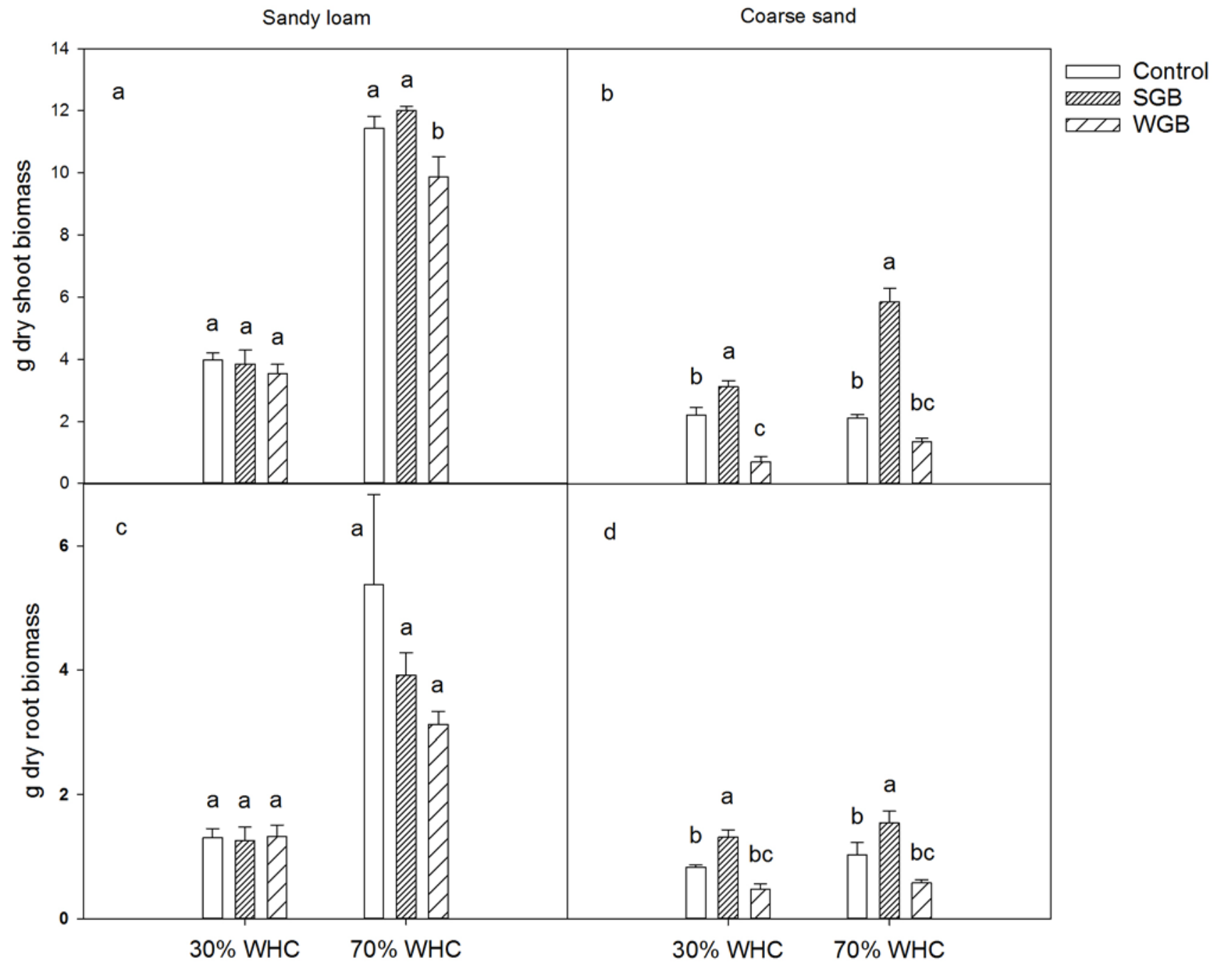

518 Fig. 2 Dry shoot biomass (g) of spring barley per pot after 6 weeks of the experimental period (a,b) 519 and dry root biomass $(c, d)$ on sandy loam soil $(a, c)$ and coarse sandy soil $(b, d)$ grown under two water 520 regimes: $30 \%$ and $70 \%$ of the water-holding capacity (WHC) of the control treatment respectively. 521 Control $=$ non-amended soil, SGB = soil with $1 \%$ straw gasification biochar and WGB = soil with $1 \%$ 522 wood gasification biochar. Values presented are means with standard error bars $(n=4)$. Different 523 letters indicate significant differences between treatments within each water regime $(P<0.05)$ 


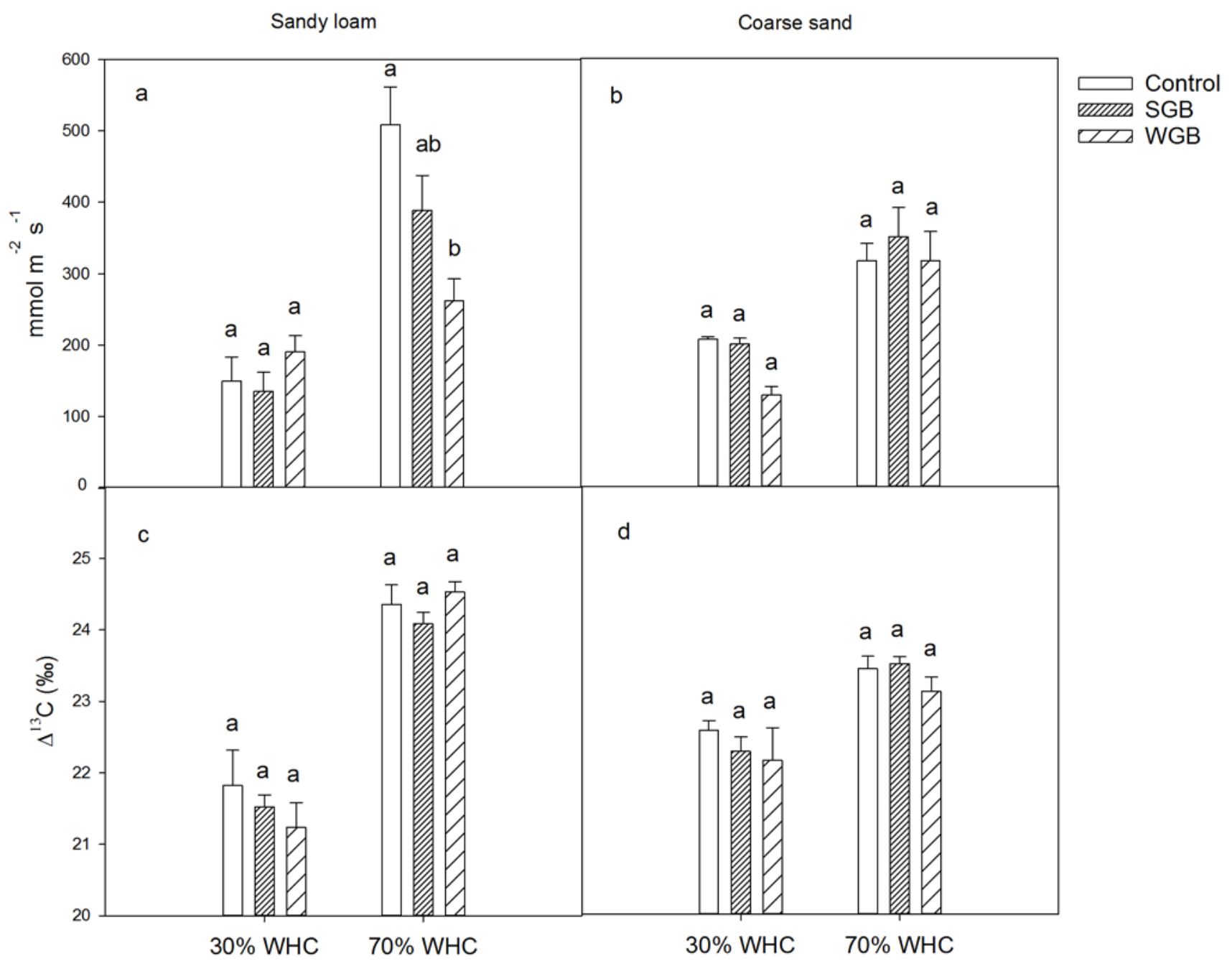

525

526 Fig. 3 Stomatal conductance of barley leaves $(\mathrm{a}, \mathrm{b})$ and carbon isotope discrimination in plant tissue $527(\mathrm{c}, \mathrm{d})$ on sandy loam soil $(\mathrm{a}, \mathrm{c})$ and coarse sandy soil $(\mathrm{b}, \mathrm{d})$ measured under two water regimes. For 528 treatment abbreviations, see Fig. 2. Values presented are means with standard error bars ( $n=4$ for 529 stomatal conductance and $\mathrm{n}=3$ for carbon isotope discrimination). Different letters indicate significant 530 differences between treatments within each water regime $(P<0.05)$ 


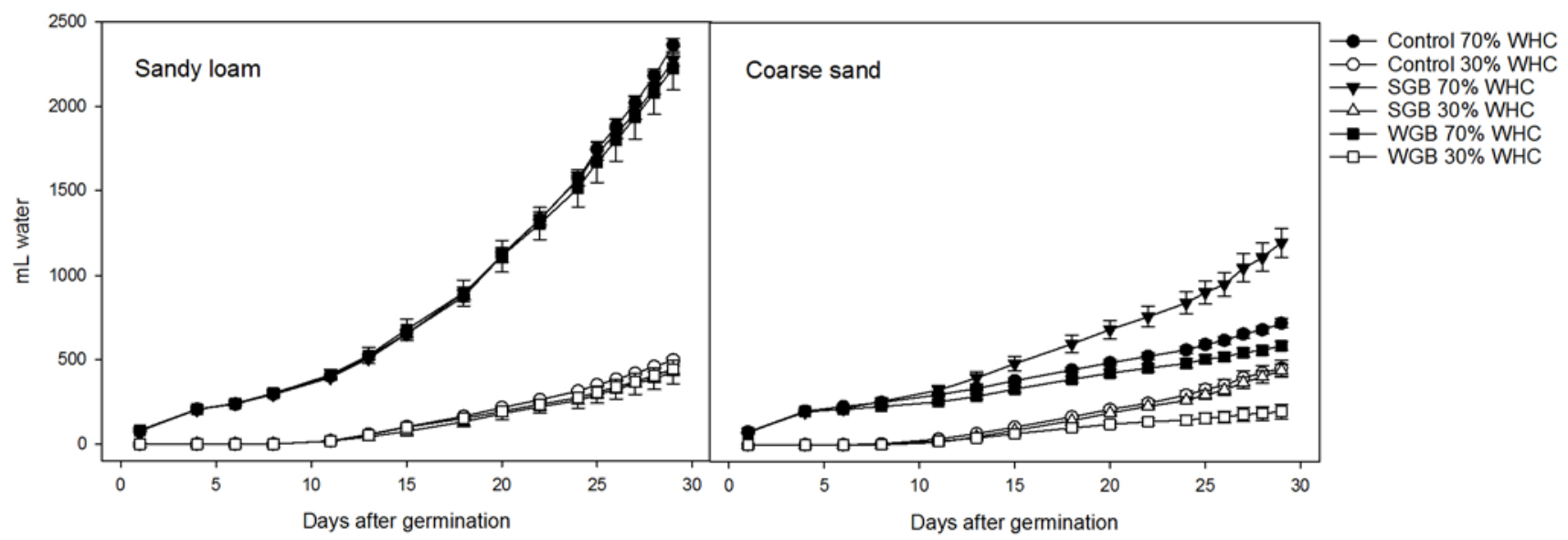

Days after germination

533 Fig. 4 Cumulative plant water consumption ( $\mathrm{mL}$ water $\operatorname{pot}^{-1}$ ) from germination until harvest in all 534 treatments in sandy loam and coarse sandy soil respectively. For treatment abbreviations, see Fig. 2. 535 Values presented are means with standard error bars $(n=4)$ 


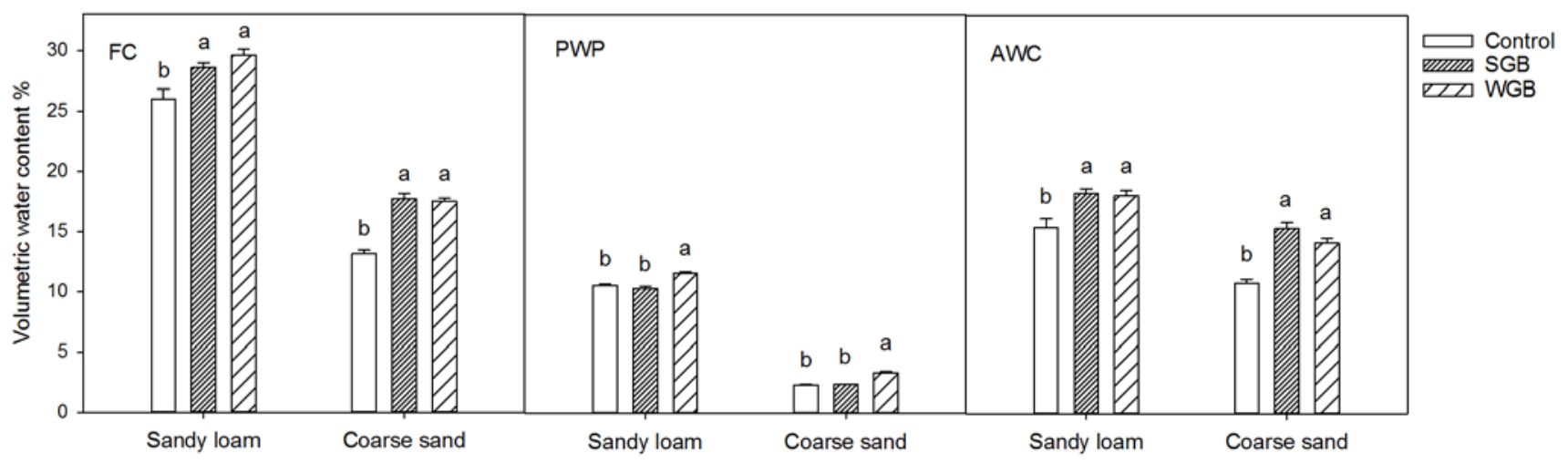

538 Fig. 5 Field capacity (FC), permanent wilting point (PWP) and available water content (AWC) measured 539 at the end of the experimental period. For treatment abbreviations, see Fig. 2. Values presented are 540 means with standard error bars $(n=4)$. Different letters indicate significant differences between 541 treatments within each soil type $(P<0.05)$ 
543

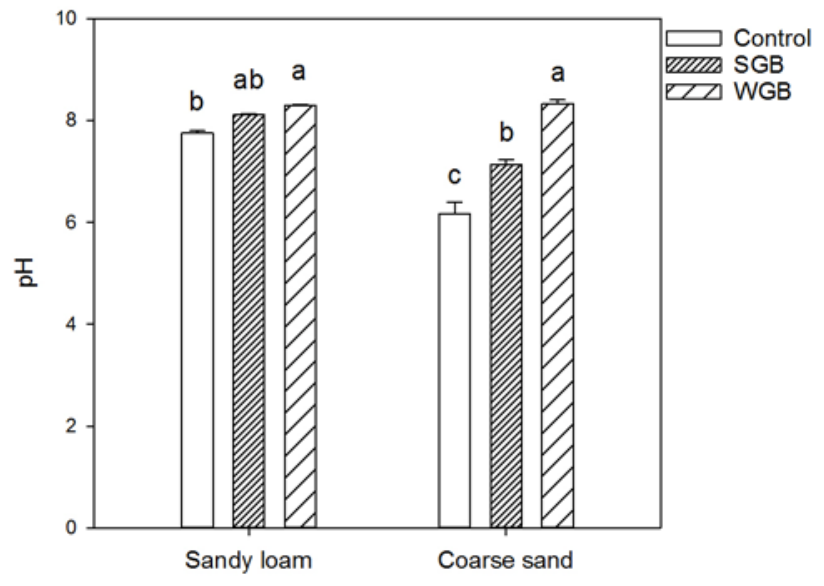

544 Fig. 6 Soil pH measured at the end of the experimental period. For treatment abbreviations, see Fig. 2.

545 Values presented are means with standard error bars $(n=3)$. Different letters indicate significant 546 differences between treatments within soil type $(P<0.05)$

547

548 